Jefferys, E. G., Brian, P. W., Hemming, H. G. \& Lowe, D. (1953). J. gen.

Microbiol. 9, 314-341.

\title{
Antibiotic Production by the Microfungi of Acid Heath Soils
}

\author{
By E. G. JEFFERYS, P. W. BRIAN, H. G. HEMMING \\ AND D. LOWE \\ Imperial Chemical Industries Limited, Butterwick Research Laboratories, \\ Welroyn, Hertfordshire
}

SUMMARY: A study has been made, using a plating technique, of the fungi occurring in acid sandy podsol soils and of their distribution at different levels of the soil profile. The most widespread species, characteristic of this type of soil, included: Absidia orchidis, Mortierella alpina, Mucor ramannianus, Penicillium frequentans, $\boldsymbol{P}$. nigricans, $\boldsymbol{P}$. roqueforti, $\boldsymbol{P}$. terlikoreskii and Trichoderma viride. A number of other species were locally abundant, including Absidia glauca, Coniothyrium sp., Gliocladium sp. (roseum series), Penicillium citrinum and Zygorhyncus moelleri.

The plate counts of viable fungal units decreased sharply from upper to lower levels, though there was occasionally a secondary maximum in the upper part of the $B$ horizon. Most species were characteristically found most abundantly in upper layers of the A horizon, but Mucor ramannianus was notable for its abundance at much lower levels; in several of the profiles examined it was isolated in almost pure culture from the $B$ horizon.

Of the sixty-five species isolated, about half produced antibiotics. Most of these were toxic to fungi and bacteria; only a few cases of specific antifungal or antibacterial activity were encountered. The Phycomycetes differed from other groups in that none produced antifungal substances. The capacity to produce antifungal antibiotics appears to be correlated with the distribution of species; of the widespread and locally abundant fungi, $45 \%$ produced such antibiotics as compared with $15 \%$ of the rare fungi. Nevertheless, certain widespread species (e.g. Absidia orchidis, Mortierella alpina, Mucor ramannianus, Penicillium roqueforti) did not produce antifungal antibiotics, so it cannot be considered to be a necessary character of widespread soil fungi. There is some evidence that such widespread non-producers of antibiotics are relatively resistant to the antibiotics produced by other species.

An attempt has been made to group the fungi isolated into Burges' ecological categories of 'sugar-fungi' and 'humus-fungi' on the basis of their capacity to attack and utilize carboxymethylcellulose (CMC). Only $26 \%$ of the fungi were unable to utilize CMC, Phycomycetes being prominent among these. Whereas $35 \%$ of the rare fungi and $54 \%$ of locally abundant fungi were 'sugar-fungi', only $17 \%$ (all Phycomycetes) of the widespread fungi were 'sugar-fungi'.

These results are believed to lend support to the view that antibiotic production is of ecological significance to soil fungi. They also provide information which can form the basis of an experimental search for more direct evidence.

The conception that antibiotic production may be of significance in the relations between soil micro-organisms stems mainly from observations of four kinds: (1) that a high proportion of soil micro-organisms, including fungi, bacteria and actinomycetes, produce antibiotics in vitro; (2) that fungi parasitic on the roots or underground stems of plants survive in soil only for 


\section{Antibiotic production by the microfungi of acid heath soils 315}

a limited time in competition with certain saprophytic organisms; (3) that among the more effective of these saprophytic antagonists are such organisms as the fungus Trichoderma viride, whose capacity to produce antibiotics in vitro is well-known; (4) that root-parasitic fungi are in general more sensitive to antibiotics than the saprophytic micro-organisms which produce them. These points have recently been dealt with more fully elsewhere (Brian, 1949 $a$, $1949 b$; Garrett, 1950, 1951). It has frequently been suggested, therefore, that the basis of the antagonism between soil-saprophytes and root-parasites is, in part at least, the production of antibiotics by the former. This hypothesis has rested mainly on circumstantial evidence and cogent arguments can be advanced against it. This paper reports one aspect of a general investigation intended to produce more direct evidence.

It seemed to us that an approach based on the study of micro-organisms, antibiotics and soils biologically unrelated to one another would not necessarily give information of value. We have therefore sought: (1) to obtain a detailed knowledge of the microflora of a well-defined type of soil and of the capacity of the species concerned to produce antibiotics in vitro; the present paper deals exclusively with this aspect and the soil fungi only are considered; (2) to obtain knowledge of the biological and chemical properties of the antibiotics produced by these organisms; this has been dealt with in several publications referred to elsewhere in this paper; (3) to determine the stability of these antibiotics in soils of the type under investigation; results have been presented by Jeffreys (1952); (4) to obtain information bearing directly on the capacity of organisms isolated from the chosen soil to produce antibiotics under soil conditions; preliminary results have been reported by Wright (1952).

The type of soil chosen for study was an acid sandy podsol, such as develops characteristically in this country on Bagshot sand deposits. Such soils are naturally poor and usually bear a heath vegetation; they have little economic value except for forestry. This type was chosen because of some evidence of occasional accumulation of biologically produced substances toxic to fungi (Neilson-Jones, 1941); it has been suggested that these toxins are antibiotics produced by certain fungal species characteristic of the soil (Brian, Hemming \& McGowan, 1945; Rayner, 1945). These soils have a well-developed profile, the chemical and physical properties of the soil differing widely in different zones of the top 2-3 ft. Since such physico-chemical differentiation would be expected to result in differences in the microflora at different levels, the soils have been studied in depth as well as at different localities on the same geological formation. Thus, in addition to providing basic material for the other investigations mentioned in the preceding paragraph, this work has provided information on the ecology of the fungi of acid heath soils and affords an interesting comparison with the survey of fungi of Breckland soils recently undertaken by Warcup (1951). 


\section{MATERIALS AND METHODS}

\section{The soils}

Soils were obtained from nine profiles exposed by digging pits of approximately $2 \mathrm{ft}$. square cross-section and depth of 15-26 in. These were all on soils derived from Bagshot sands, four on Bagshot Heath, Surrey, and five on Wareham Heath, Dorset. The structural and physical characteristics of these profiles are summarized in Tables 2-10; all were highly acid at all levels. The majority of these soils were well-developed podsols but some, as was noted by Neilson-Jones (1941), rested directly on the subsoil without a pan.

\section{Sampling}

After exposure of the profile, the surface was picked off with a sterile stainless steel tool, to reduce the possibilities of contamination of the lower layers by soil from upper layers during digging. Fairly large samples (c. 200 g.) of soil were then taken from different layers, again using sterile tools, and placed in sterile screw-capped bottles. Dates of sampling were: profiles I-IV, 13 October 1947; profiles V-IX, 29 January 1948.

\section{Isolation of organisms}

The conventional plating technique was adopted. Each soil sample was well mixed, a weighed portion of the order of $25 \mathrm{~g}$. was added to $250 \mathrm{ml}$. sterile water in a flask and shaken well by hand for $15 \mathrm{~min}$. Three further tenfold dilutions of this suspension were made with sterile water; $1 \mathrm{ml}$. samples of these were used to inoculate the surface of agar plates incubated at $25^{\circ}$ for 6 days previously. The moisture contents of the soils were determined, so that the number of colonies appearing on each plate could be related to the numbers of viable units per g. dry soil. In general, eight plates were inoculated with each dilution and were incubated at $25^{\circ}$. Colony counts were made after 6 days. The plates were kept for some time after this and examined from time to time in case new colonies developed.

The medium used for isolation had the following composition: $\mathrm{KH}_{2} \mathrm{PO}_{4}$, 1.0 g.; $\mathrm{MgSO}_{4} .7 \mathrm{H}_{2} \mathrm{O}, 0.5 \mathrm{~g}$.; ammonium tartrate, $2 \cdot 2 \mathrm{~g}$.; $d l$-malic acid, $5 \cdot 0 \mathrm{~g}$.; peptone, 1.0 g.; yeast extract (Difco Laboratories Inc., Detroit), 1.0 g.; glucose ('Dextrolact'-Corn Products Ltd., Strand, London, W.C. 2), 20.0 g.; minor element mixture, containing iron, manganese, copper, zinc and molybdenum, as described by Brian, Curtis \& Hemming (1947), 1.0 ml.; Rose Bengal, 0.067 g.; agar, 25.0 g.; distilled water to 1 l. This somewhat complex medium was used to ensure that organisms requiring ammonia or aminonitrogen, or vitamins, were not excluded. The malic acid was included as a result of work which showed that certain organic acids aid the development of some fungi on ammonia-nitrogen media (Brian et al. 1947). Preliminary experiments showed that appreciably greater numbers of colonies developed on this medium than on other media recommended for isolation of fungi from soil. 


\section{Antibiotic production by the microfungi of acid heath soils $\mathbf{3 1 7}$}

Representative colonies were subcultured on slopes; at the same time a note was made of the frequency of similar colonies, on a simple arbitrary scale (see Tables 2-10). About 950 isolations were made in this way for subsequent examination and identification.

The soils were not all plated immediately after collection, but were stored in a refrigerator until used. The actual dates of plating were: profile $\mathbf{I}$, 14 October 1947; profile II, 28 October 1947; profile III, 12 November 1947; profile IV, 26 November 1947; profiles V and VI, 30 January 1948; profile VII, 9 April 1948; profile VIII, 23 April 1948; profile IX, 30 April 1948.

On each occasion when soils were plated, control plates were poured and handled in every way like the dilution plates except that they received no soil inoculum. Organisms appearing both on the control plates and the soil dilution plates were considered to be contaminants from the laboratory air.

\section{Determination of antibiotic activity}

All the representative subcultures were tested by a streak test on agar media (Brian, Curtis, Hemming, Jefferys, Unwin \& Wright, 1951) for antagonism to the fungus Candida albicans and the bacteria Staphylococcus aureus, Salmonella typhi and Bacterium coli. A somewhat smaller selection of isolates of each species was grown in liquid media $(30 \mathrm{ml}$. in $100 \mathrm{ml}$. flasks) and the culture filtrates were assayed from time to time by the Botrytis allii spore germination test (Brian \& Hemming, 1945) and by Bacillus subtilis and Bacterium coli cylinder plate assays. The media used were those of Czapek-Dox and Raulin-Thom, each containing $5 \%$ glucose ('Dextrolact'). Some fungi failed to develop on these media, but did so when $0 \cdot 01-0.1 \%$ 'Difco' yeast extract was added.

\section{Utilization of carboxymethyl cellulose}

A medium of the following composition was dispensed in $10 \mathrm{ml}$. quantities in $100 \mathrm{ml}$. flasks: ammonium tartrate, 2.0 g.; potassium dihydrogen phosphate, 1.0 g.; magnesium sulphate (hydrated), 0.5 g.; potassium chloride, $0.5 \mathrm{~g}$.; ferrous sulphate, $0.01 \mathrm{~g}$.; sodium carboxymethylcellulose, degree of substitution, 0.45-0.5 mol. ('Cellofas' B-I.C.I. Ltd., Nobel Division, Stevenston, Ayrshire), 10.0 g.; distilled water, 1 l. After autoclaving, replicate flasks were inoculated with the fungi to be tested. Flasks were harvested after 5 and 10 days' incubation at $2^{\circ}$ and the culture filtrates were tested for carboxymethylcellulose (CMC) with chlor-zinc-iodide (Gatenby \& Beams, 1950). This reagent reacts with CMC as with cellulose. The uninoculated medium gave a dark blue precipitate with chlor-zinc-iodide. After growth of some fungi no colour reaction was obtained, indicating complete degradation of CMC. A reaction similar to that obtained with uninoculated medium was taken to indicate no degradation of CMC and intermediate reactions partial degradation.

CMC was used as a test substrate in preference to cellulose since, being water-soluble, it is more convenient to handle. It was realized that some 


\section{E. G. Jefferys, P. W. Brian, H. G. Hemming and D. Lowe}

fungi able to degrade CMC might be unable to degrade cellulose (Siu, 1951). However, of sixty-two strains (33 spp.) found to attack CMC vigorously, fifty-eight strains (32 spp.) were found to attack cellulose in similar tests using cellulose powder (Whatman B quality, chemically prepared, standard grade for chromatography) instead of CMC. For cellulose powder iodine and sulphuric acid were found preferable to replace the chlor-zinc-iodide reagent (Gatenby \& Beams, 1950).

\section{RESULTS}

Species isolated. The species isolated are listed in Table 1 below.

\section{Table 1. List of species isolated}

(The data in parentheses denote their capacity to attack carboxymethylcellulose and the number of cultures tested for this activity; these are referred to elsewhere in the text.)

\section{Phycomycetes}

Absidia glauca Hagem (CMC -, 2)

A. orchidis (Vuill.) Hagem (CMC -, 2)

Mortierella alpina Peyronel (CMC -, 3)

M. isabellina Oudemans (CMC -, 3)

M. vinacea Dixon-Stewart (CMC -, 1)

Mucor racemosus Fres. (CMC,+ 1$)$

M. ramannianus Moeller $(\mathrm{CMC}+, 6)$

M. varians Povah $(\mathrm{CMC}+, 1)$

Pilaira anomala (Cesati) Schroeter (CMC -, 1)

Zygorhyncus moelleri Vuill. (CMC -, 2)

Ascomycetes

Sordaria fimicola (Rob.) Ces. \& De Not. (CMC + +, 2)

FUNGI IMPERFECTI

Sphaeropsidales

Coniothyrium sp. 977 (CMC,++ 3$)$

Phoma spp. 802 (CMC,++ 1$), 1015(\mathrm{CMC}++, 1)$, $1079(\mathrm{CMC}+, 1)$

Melanconiales

Pestalotia sp. $799(\mathrm{CMC}++, 1)$

Moniliales

Aspergillus ruber (Spieckermann \& Bremer) Thom \& Church (CMC -, 5)

Aspergillus sp. 912 (CMC,+ 1$)$

Cephalosporium acremonium Corda (CMC -, 1)

(Cladosporium herbarum Link ex Fr.) (CMC,++ 6$)$

Gliocladium sp. 650 (roseum series) (CMC variable, see p. 335)

Gliomastix convoluta (Harz) Mason (CMC,++ 1$)$

Oidiodendron griseum Robak (CMC,++ 1$)$

Papularia sphaerosperma (Pers.) von Höhnel (CMC $++, 1)$

Penicillium adametzi Zaleski (CMC -, 2)

P. albidum Sopp (CMC,++ 3$)$

P. charlesii Smith (CMC,++ 1$)$

$P$. chrysogenum Thom (CMC -, 1)
P. citreoviride Biourge (CMC -, 2)

P. citrinum Thom (CMC,++ 3$)$

$P$. fellutanum Biourge (CMC,+ 1$)$

$P$. frequentans Westling, form A $(\mathrm{CMC}++, 2)$

$P$. frequentans Westling, form B (CMC,++ 4$)$

$P$. godlewskii Zaleski (CMC,++ 2$)$

$P$. lanosum Westling (CMC,++ 5$)$

$\boldsymbol{P}$. lividum Westling $(\mathrm{CMC}++, 2)$

$P$. melinii Thom (CMC,+ 4$)$

$P$. nigricans (Bainier) Thom, form A $($ CMC,++ 5$)$

$P$. nigricans (Bainier) Thom, form B (CMC,++ 3$)$

$P$. notatum Westling (CMC,++ 1$)$

$P$. palitans Westling $(\mathrm{CMC}++, 1)$

P. paxilli Bainier (CMC -, 1)

P. roqueforti Thom $(\mathrm{CMC}++, 3)$

P. rubrum Stoll $(\mathrm{CMC}++, 1)$

$P$. spinulosum Thom (CMC variable, see p. 335)

(P. stoloniferum Thom) (CMC,++ 3$)$

P. tardum Thom (CMC -, 1)

P. terlikowskii Zaleski $(\mathrm{CMC}++, 3)$

P. thomii Maire (CMC,++ 3$)$

$P$. urticae Bainier (CMC,+ 1$)$

Penicillium sp. 895 (? nigricans series) (CMC,+ 4$)$

Penicillium sp. 1006 (raistrickii series) (CMC +, 4)

Pullularia pullulans (de Bary \& Low) Berkhout

(CMC -, 1)

Scopulariopsis spp. 909 (CMC -, 1), 1005 (CMC + +, 1), $1068(\mathrm{CMC}+, 1)$

Sporotrichum sp. 1038 (? roseum Link) (CMC,++ 4$)$

Torula spp. 781 (CMC - , 1), 787 (CMC -, 1)

Trichocladium asperum (Corda) Harz (CMC,++ 1$)$

Trichoderma viride Pers. ex Fr. (CMC,++ 7 )

Verticillium sp. 1027 (? terrestre (Link) Lindau) (CMC variable, see p. 335)

\section{Mycelia sterilia}

Sclerotium sp. 1077 (CMC -, 2)

'Fungus A' (1066) (CMC,++ 1$)$

'Fungus B' (1067) (CMC,++ 1$)$ 


\section{Antibiotic production by the microfungi of acid heath soils 319}

The following monographs have been used in compiling this list: for Penicillium, Raper \& Thom (1949); for Aspergillus, Thom \& Raper (1945); for Mortierella, Linnemann (1941); for other Phycomycetes, Zycha (1935) and Naumov (1939).

Species identified to genus only have been given code numbers in the list. A number of species which occurred frequently on control plates and which are believed to be laboratory atmosphere contaminants have not been included. The more important of these contaminant species were several fasciculate penicillia (Penicillium cyclopium Westling, $\boldsymbol{P}$. expansum Link, $\boldsymbol{P}$. gladioli Machacek, $\boldsymbol{P}$. puberulum Bainier) and two Aspergilli (Aspergillus sydowi (Bain. \& Sart.) Thom \& Church, A. repens (Corda) de Bary). Two other species appeared both on control plates and on soil-dilution plates-Penicillium stoloniferum and Cladosporium herbarum. Their appearance on the soildilution plates was on some occasions so regular that it seemed possible that they did occur in the soil as well as in the laboratory air. They have therefore been included in parentheses in Table 1 to indicate the doubt about their real status. Warcup (1951) also had doubts concerning the status of $C$. herbarum.

A few species remained completely unidentified. Most of these were slowgrowing dark-coloured moulds of rare occurrence; they have not been considered further. Two white sterile fungi were of frequent occurrence in some soils and are included in the list of species isolated and referred to as 'fungus A' and 'fungus $B$ '. These are possibly Basidiomycetes, though no clampconnexions were seen.

Elsewhere in the text it will be shown that in each of the two species Penicillium nigricans and $\boldsymbol{P}$. frequentans, two forms could be distinguished on biochemical and cultural characters. In all statistical material in subsequent parts of the text these are counted as distinct species. It is worthy of note that of the 65 species isolated 28 were species of Penicillium.

\section{Distribution of fungi in the soil profiles}

Total plate counts, which may be regarded as an imprecise measure of the number of viable fungal units in each gram of dried soil, and the species isolated from different levels of each soil profile are shown in Tables 2-10. The abundance of each species at each level is recorded on a,,++++++ system.

Plate counts were highest in the surface layers and fell sharply in the lower layers. In some of the profiles which had a well-defined B horizon, there were indications of an increased plate count in the upper, humus-accumulating layer of the $B$ horizon, as compared with that in the leached $A_{2}$ horizon immediately above. The number of species isolated was also generally greatest in surface layers, but this fell off much less rapidly in depth than the plate count.

The plate count in surface layers varied considerably from profile to profile. In general, counts were higher where there was a definite surface layer of litter or humus. In profile IX the low numbers of species and the low plate 


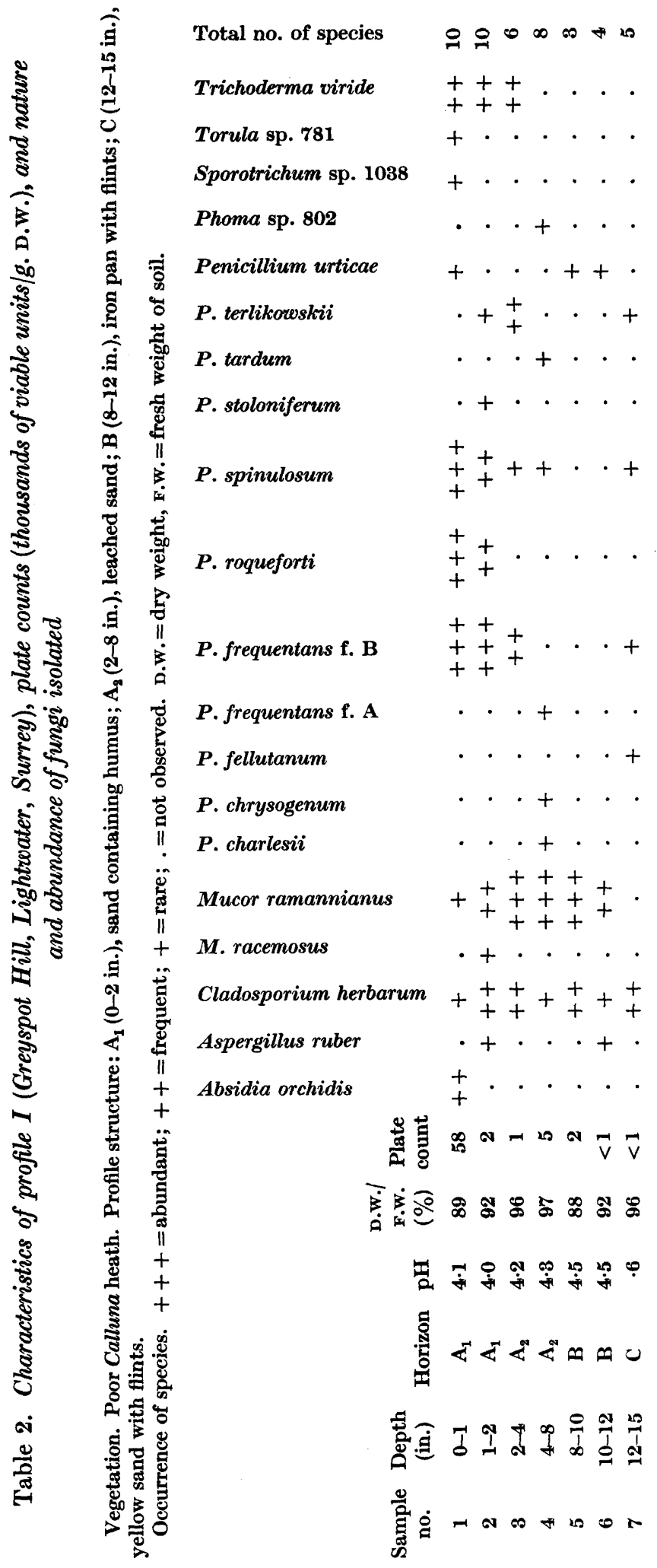




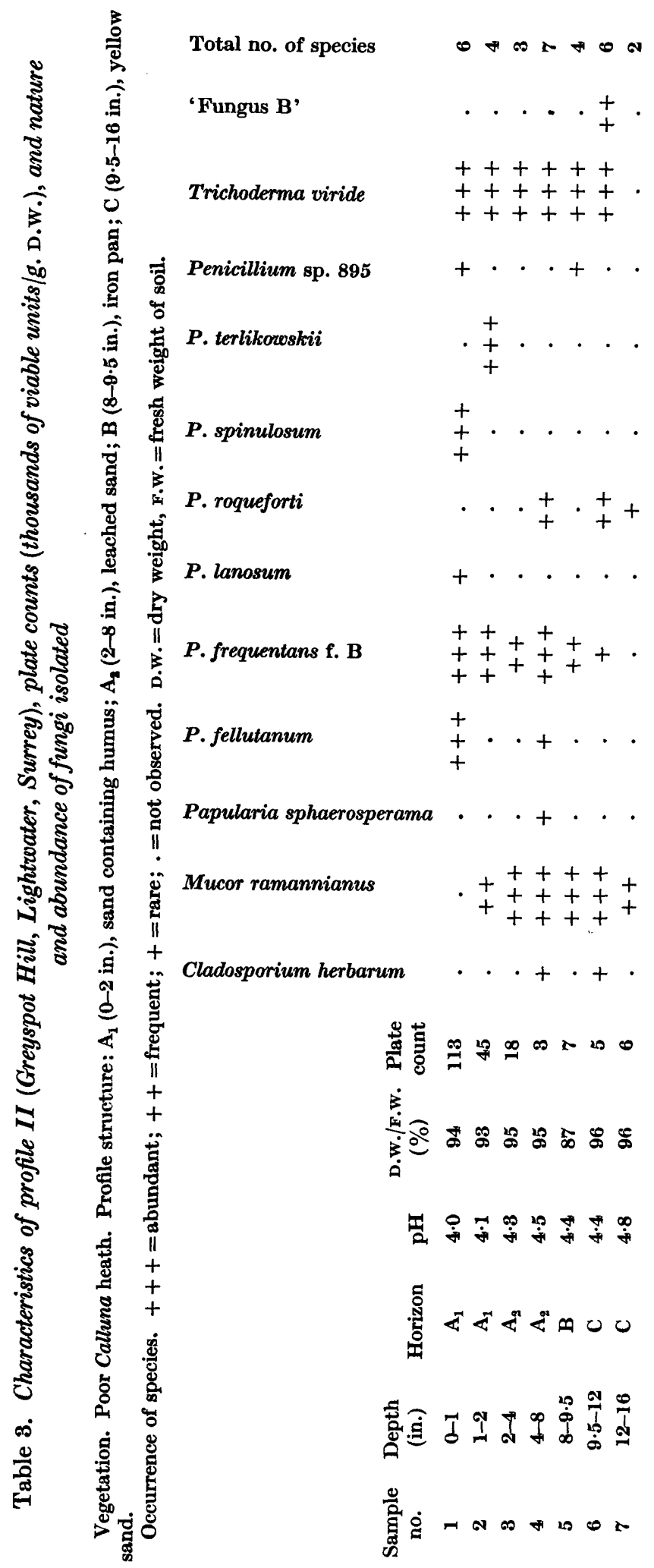




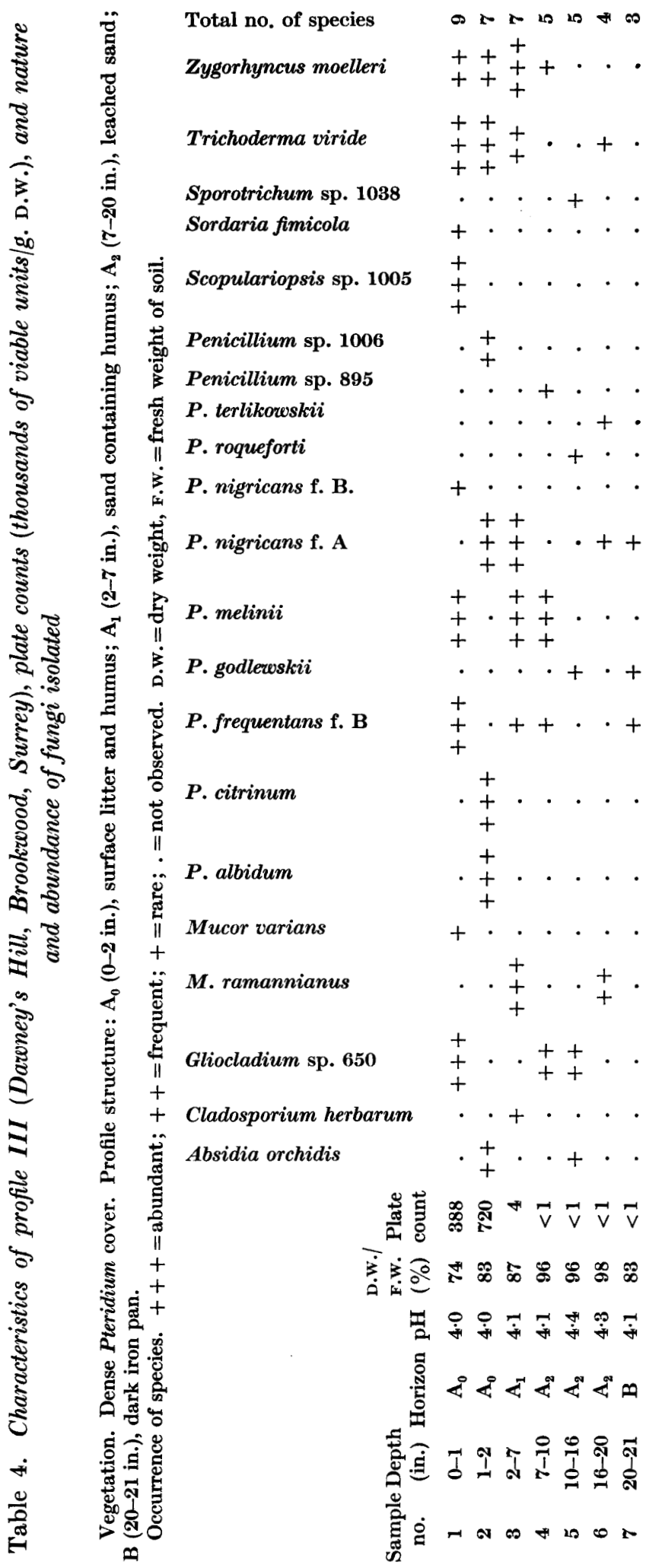




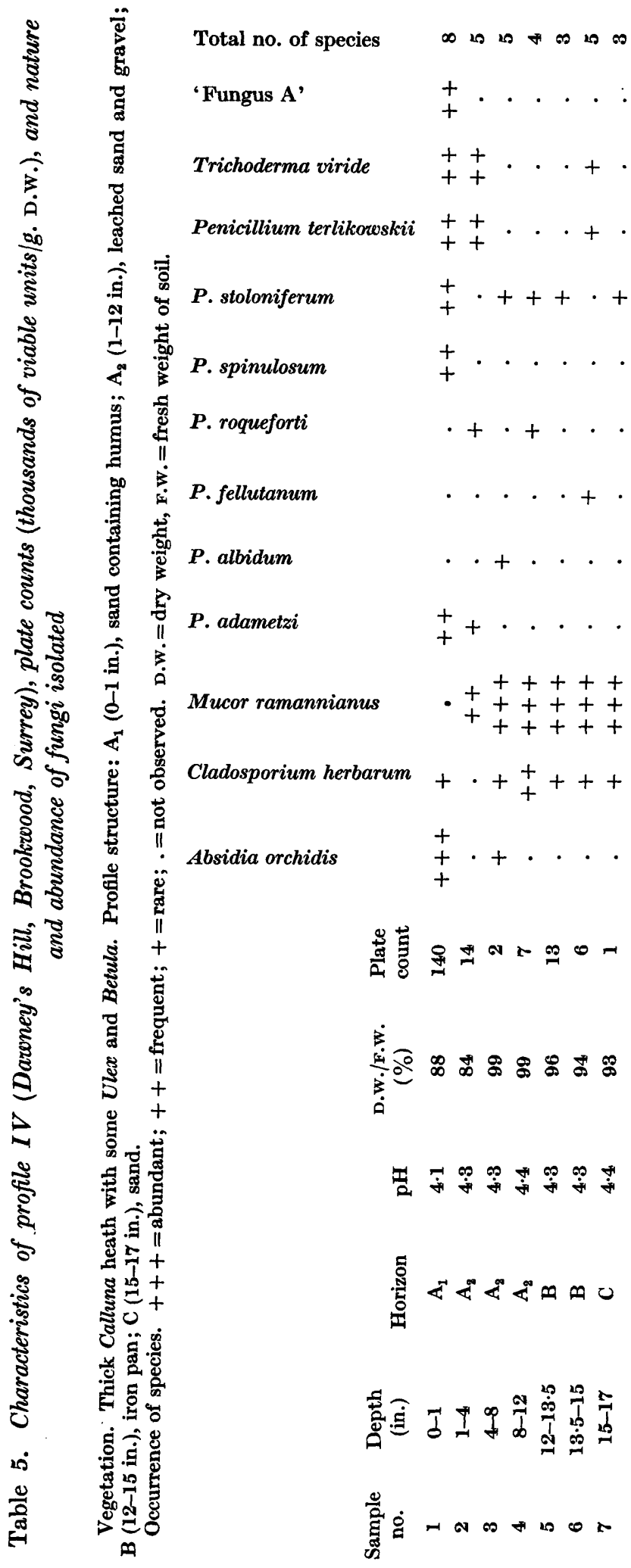




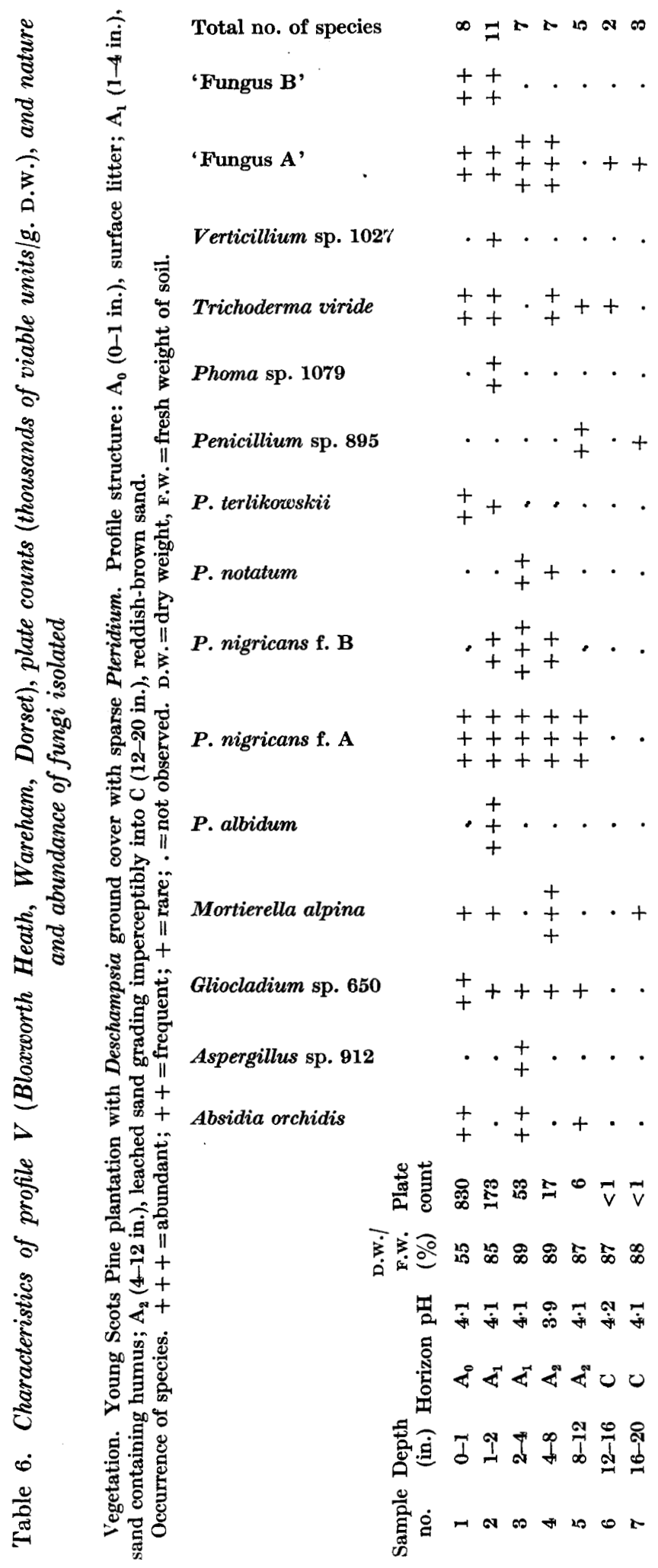




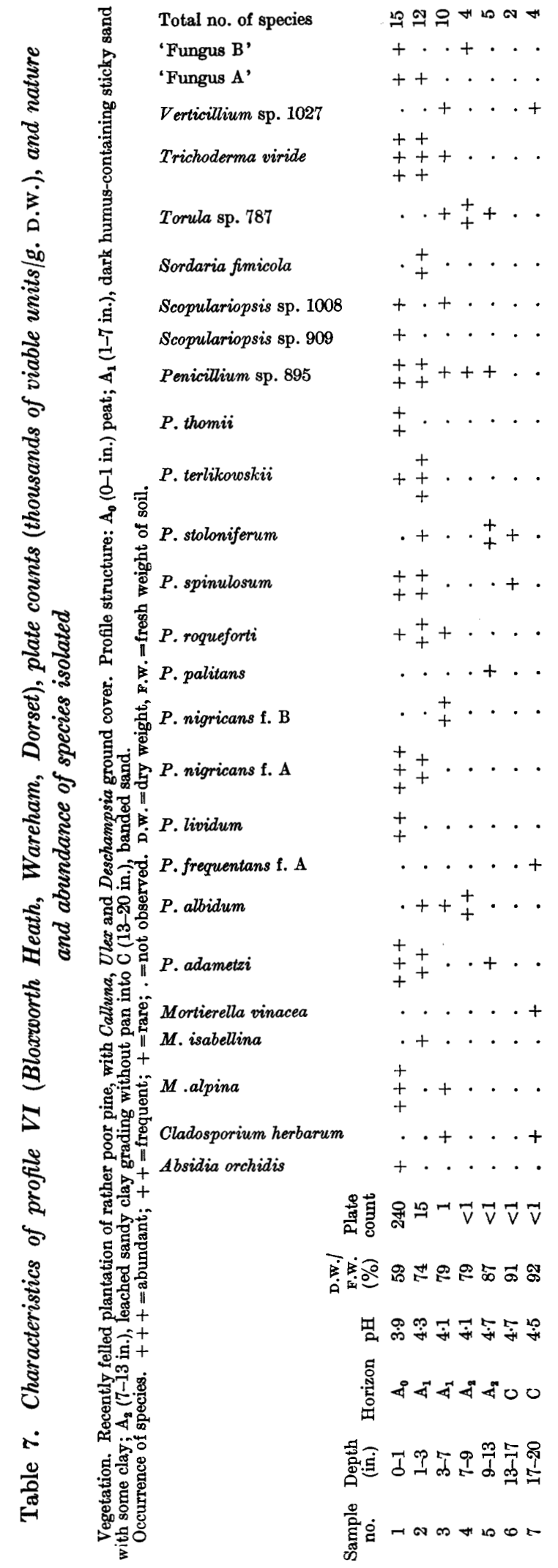




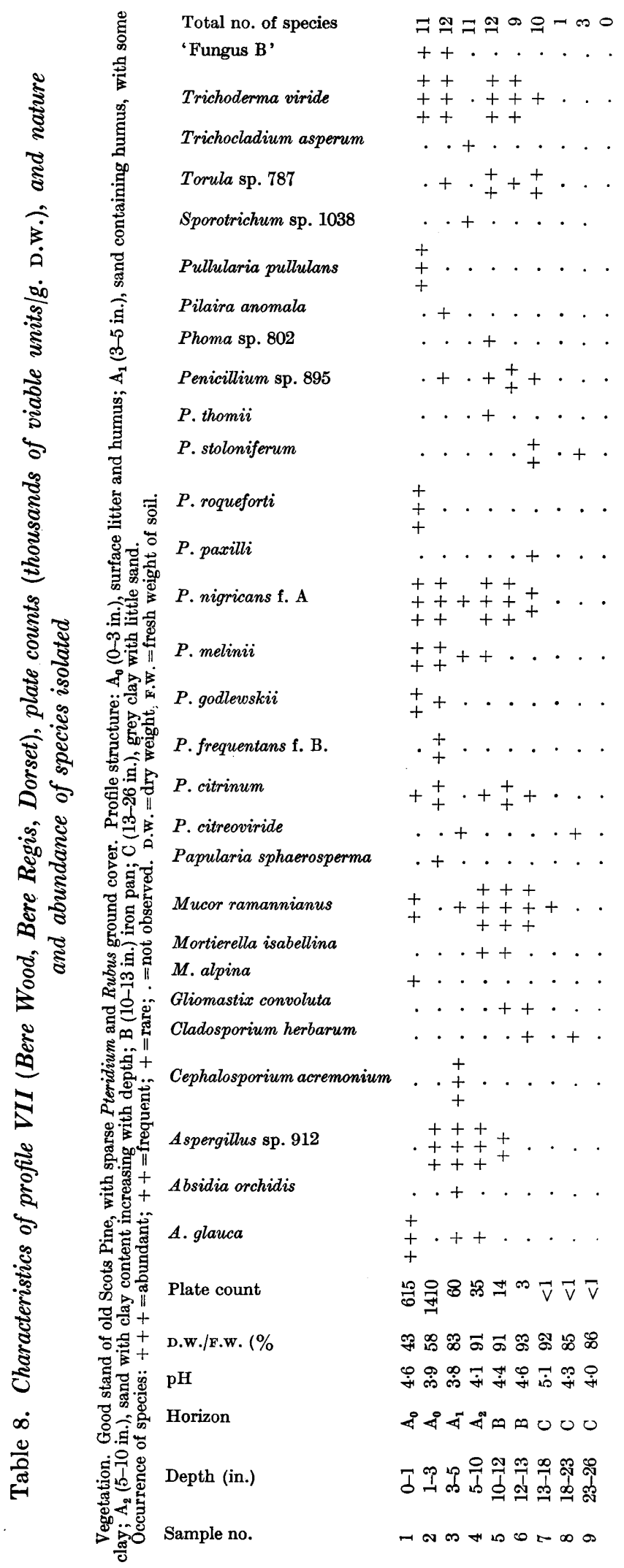




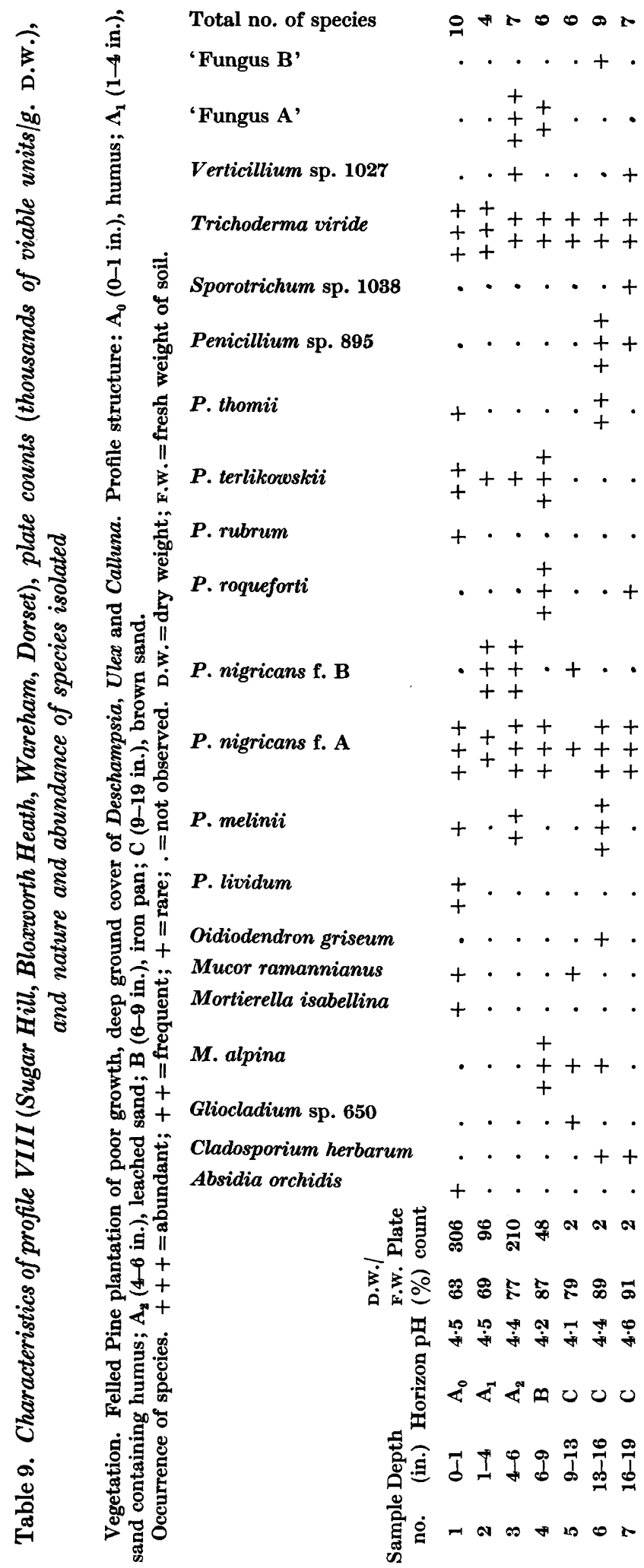




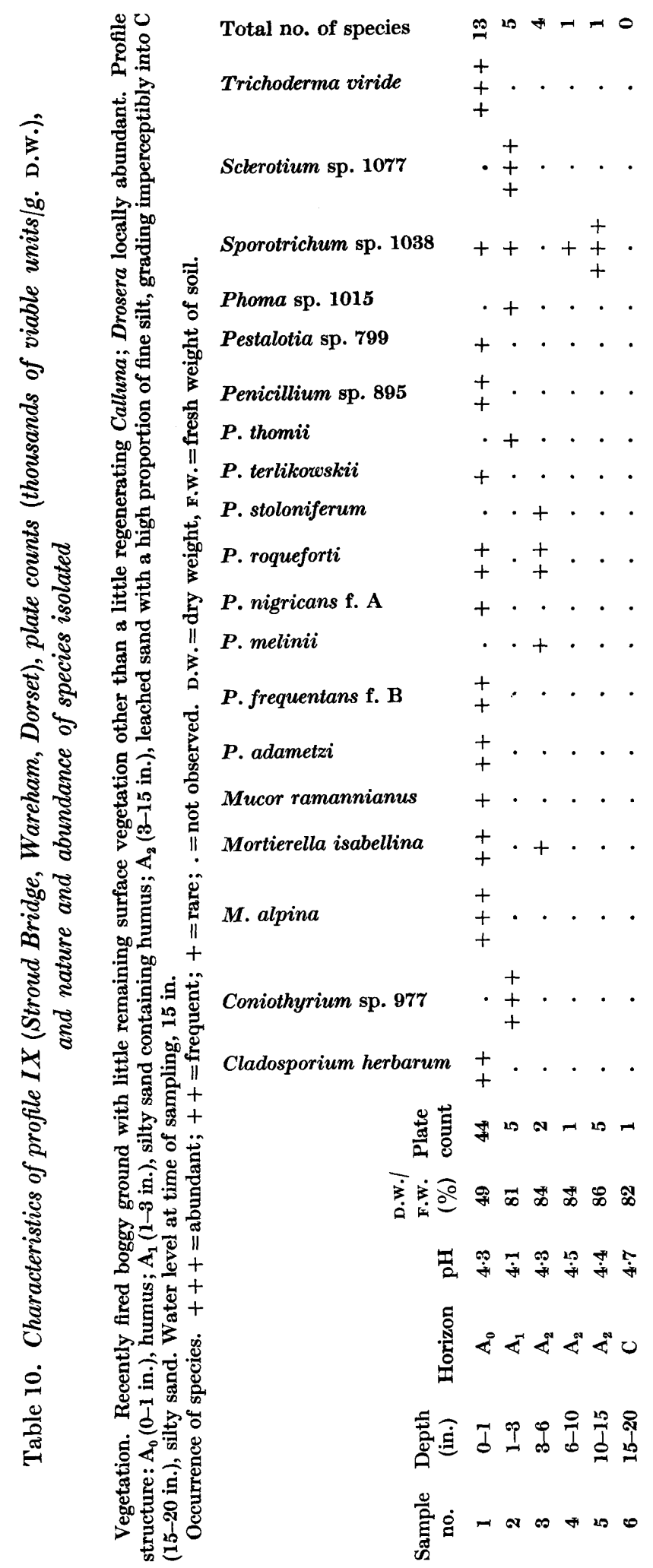


counts in all but the uppermost samples are probably a result of waterlogging.

The distribution of species is discussed in a later section of this paper.

\section{Antibiotic production}

As explained earlier, all representative cultures were tested for antibiotic production by an agar streak test and selected cultures were tested in liquid media. After each species listed below, two numbers are given; the first is the number of cultures tested in the agar streak test, the second is the number tested in liquid media. For convenience, species which have shown consistent indication of antibiotic production by the tests described are called 'active' species, those which have not are called 'inactive'.

\section{Phycomycetes}

The following species were inactive in both tests:

Absidia orchidis $(12 ; 2)$, Mucor racemosus $(1 ; 1), M$. varians $(1 ; 1)$, Pilaira anomala $(1 ; 1)$, Zygorhyncus moelleri $(8 ; 2)$. Some isolates of the following species showed signs of antibacterial activity in the streak test, not unequivocally confirmed in liquid media: Mortierella alpina $(19 ; 1), M$. isabellina $(7 ; 4), M$. vinacea $(1 ; 1)$. They showed no antifungal activity.

Two species showed more definite activity:

Absidia glauca $(3 ; 2)$. Although no activity was seen in agar streak tests, both cultures tested on liquid media produced culture filtrates slightly but definitely inhibitory to Bacillus subtilis.

Mucor ramannianus $(47 ; 8)$. Only one isolate was inactive in the streak test; all the remainder inhibited Staph. aureus and thirty-five inhibited Salmonella typhi. In liquid media, seven isolates produced culture filtrates inhibitory to Bacillus subtilis.

It is worthy of note that no antifungal activity has been shown by either of these species. This suggested that the inhibition of bacteria might have been a simple effect of $\mathrm{pH}$, but the observed data do not support this view. No antibiotic has yet been isolated.

\section{Ascomycetes}

Sordaria fimicola $(2 ; 2)$ was inactive in both tests.

\section{FUNGI IMPERFECTI}

Sphaeropsidales. Phoma spp. $802(5 ; 2), 1015(2 ; 1)$ and $1079(1 ; 1)$ were inactive or nearly so in both tests.

Coniothyrium sp. $977(3 ; 3)$. All isolates were generally antibacterial in the streak test. Suitable liquid media for adequate growth have not yet been found, but in such experiments as have been done the culture filtrates were slightly but definitely inhibitory to Bacillus subtilis and caused a rather unusual distortion of germ-tubes of Botrytis.

Melanconiales. Pestalotia sp. $799(1 ; 1)$ was inactive in both tests. 
Moniliales. The following species were inactive in both tests:

Aspergillus ruber $(2 ; 1)$, Cephalosporium acremonium $(3 ; 2)$, Cladosporium herbarum $(53 ; 7)$, Gliomastix convoluta $(2 ; 2)$, Penicillium charlesii $(1 ; 1)$, $\boldsymbol{P}$. citreoviride $(6 ; 2), \boldsymbol{P}$. fellutanum $(3 ; 2), \boldsymbol{P}$. lanosum $(1 ; 1), P$. roqueforti $(22 ; 4)$, P. thomii (7; 3), Penicillium sp. 895 (22; 4), Scopulariopsis sp. 1005 (1; 1), Scopulariopsis sp. $1068(2 ; 1)$, Sporotrichum sp. $1038(12 ; 3)$, Torula sp. 787 (12; 3), Torula sp. $781(1 ; 1)$, Trichocladium asperum $(1 ; 1)$.

Active species are dealt with in turn below :

Aspergillus sp. $912(7 ; 2)$. This appears to be a previously undescribed species. In the agar streak test two strains were inactive. All the remaining five showed some antibacterial activity, two of them being markedly inhibitory to all the test bacteria and to Candida albicans. Both strains tested in liquid media slightly but definitely inhibited Botrytis and inhibited $\boldsymbol{B}$. subtilis and Bact. coli markedly.

Gliocladium sp. 650 (roseum series) $(9 ; 5)$. In the streak test four isolated were inhibitory to Staph. aureus. Five isolates, including some of those inactive in the streak test, all produced culture filtrates in liquid media inhibiting Botrytis and B. subtilis. From one of these the related antibiotics gliorosein, rubrogliocladin and aurantiogliocladin have been obtained (Brian, Curtis, Howland, Jefferys \& Raudnitz, 1951; Vischer, 1953).

Oidiodendron griseum $(1 ; 1)$ gave marked antibacterial activity in liquid media, though not in the streak test.

Papularia sphaerosperma $(1 ; 1)$ was inactive in the agar streak test but in liquid media slightly but definitely inhibited Botrytis and $\boldsymbol{B}$. subtilis.

Penicillium adametzi $(11 ; 2)$. Nearly all strains were quite inactive in the streak test; two showed traces of antifungal or antibacterial activity. In liquid media both strains tested produced culture filtrates slightly toxic to Botrytis.

P. albidum $(9 ; 5)$. All nine isolates inhibited all the test bacteria in the agar streak test and all but two also inhibited Candida albicans. Five isolates grown in liquid media produced antifungal and antibacterial culture filtrates. The antibiotic albidin has been obtained from an earlier isolation of this species (Curtis \& Grove, 1947; Curtis, Hemming \& Unwin, 1951) and also from one of the isolates made in this study (Curtis, unpublished results).

$P$. chrysogenum $(1 ; 1)$. This isolate inhibited Staph. aureus in the agar streak test and in liquid media produced culture filtrates inhibitory to $B$. subtilis and slightly but definitely inhibitory to Botrytis. The antibacterial activity is probably due to penicillin but the nature of the antifungal substance is unknown.

$\boldsymbol{P}$. citrinum $(4 ; 3)$. These strains differed from typical $\boldsymbol{P}$. citrinum in that the chains of spores were not strictly columnar; they undoubtedly fall into the $\boldsymbol{P}$. citrinum series and since they produce yellow colours in reverse on Czapek agar it seems preferable to group them as $\boldsymbol{P}$. citrinum rather than $P$. steckii, the only other possibility. All were inhibitory to Staph. aureus in the streak test, two strains also inhibited Salmonella typhi. In liquid media they produced yellow, antibacterial and slightly antifungal culture filtrates. 


\section{Antibiotic production by the microfungi of acid heath soils 331}

On adding ferric chloride, a thick brown precipitate was formed, dissolving in excess ferric chloride. This strongly suggests production of the antibiotic citrinin, a well-known metabolic product of this species.

$\boldsymbol{P}$. frequentans. Two forms of this species were isolated, differing in colonial appearance and antibiotic production. One of these (form A) was typical of the species as described by Raper \& Thom (1949); colonies on Czapek agar were broadly spreading, dark green and with abundant yellow-brown pigment in reverse. The other (form B) was a light greyish-green colour with the reverse uncoloured or pale yellow.

Form $A(3 ; 0)$. Two strains were inactive in the streak test and two showed slight general antibacterial activity. From strains of similar appearance we have obtained citromycetin, an antibiotic of low activity (Grove \& Brian, 1951).

Form $B(29 ; 12)$. In the streak test three isolates inhibited all the test organisms, ten inhibited all the bacteria but not Candida, and three inhibited at least one of the test bacteria. In liquid media ten of the twelve strains tested produced culture filtrates inhibiting Botrytis strongly and $B$. subtilis moderately. The antibiotic frequentin has been isolated (Curtis, Hemming \& Smith, 1951).

$P$. godleroskii $(3 ; 3)$. Two isolates were antibacterial in the streak test and one was inactive. All produced highly antifungal and antibacterial culture filtrates in liquid media. No antibiotic has yet been isolated.

$P$. lividum $(4 ; 1)$. Three isolates were inactive in the streak test but one was inhibitory to all the organisms. This isolate produced slightly antibacterial and antifungal culture filtrates in liquid media.

P. melinii $(14 ; 6)$. Six isolates showed general antibacterial and slight antifungal activity; the remainder were inactive. Of the six strains tested in liquid media, four were inactive. The remaining two strains produced highly antifungal culture filtrates with some activity against $B$. subtilis. No antibiotic has yet been isolated.

$P$. nigricans. Two forms of this species were isolated differing in colonial appearance and antibiotic activity. One produced deeply floccose colonies, sporulating well on Czapek agar and with a pronounced and characteristic mouldy smell; this (form $\mathbf{A}$ ) was the same as that we have previously worked with under the name $\boldsymbol{P}$. janczerwskii Zal. Form $\mathbf{B}$ was more broadly spreading, much thinner and less floccose, sporulation on Czapek agar was scanty and the odour was less pronounced. Form $A$ was much more common than form $B$.

Form A $(64 ; 5)$. Fifty-three isolates inhibited only Candida in the streak test; three strains inhibited one or more of the bacteria in addition; the remainder were inactive. All of the five strains tested produced culture filtrates in liquid media which produced distortion of Botrytis germ-tubes characteristic of griseofulvin; from some of these strains griseofulvin and dechlorogriseofulvin have been isolated (Brian, Curtis \& Hemming, 1946; Grove \& McGowan, 1947; Brian, 1949c; Brian, Curtis \& Hemming, 1949; MacMillan, 1951; Grove, MacMillan, Mulholland \& Rogers, 1952). 


\section{E. G. Jefferys, P. W. Brian, H. G. Hemming and D. Lowe}

Form B (13; 3). Eleven strains showed activity against all test organisms. In liquid media culture filtrates moderately active against Botrytis and B. subtilis were produced. It seems likely that this activity is due to production of albidin, previously shown to be produced by the closely related P. albidum.

$P$. notatum $(2 ; 1)$. Though both isolates were inactive in the streak test, one was grown in liquid media and produced culture filtrates inhibitory to $B$. subtilis. This activity was probably due to penicillin, but the amount formed was certainly small.

$P$. palitans $(3 ; 1)$. One isolate inhibited Candida in the streak test, the others were inactive. The active strain produced highly antifungal culture filtrates in liquid media. The antibiotic frequentin (also produced by $P$. frequentans) has been isolated together with the chemically related substance palitantin which, however, is antibiotically inactive (Birkinshaw, 1952; Curtis \& Duncanson, 1952).

$P$. paxilli $(2 ; 1)$. Both isolates showed antibacterial and antifungal activity in the streak test. One was tested in liquid media and was found to produce culture filtrates with marked 'germ-tube stunting' activity against Botrytis characteristic of that produced by mycophenolic acid. From another isolate of this species, which showed similar activity, mycophenolic acid was isolated (Brian, 1951).

P. rubrum $(1 ; 1)$ caused inhibition of Salmonella typhi in the streak test and produced culture filtrates in liquid media slightly inhibitory to Botrytis and B. subtilis.

$P$. spinulosum $(16 ; 5)$. All isolates were inactive in the streak test, but four produced, in liquid media, culture filtrates moderately inhibitory to Botrytis and $\boldsymbol{B}$. subtilis.

$P$. stoloniferum $(25 ; 3)$. Candida was inhibited in the streak test by twentyone isolates, the remainder being inactive. The three isolates grown in liquid media produced culture filtrates slightly inhibitory to $B$. subtilis and causing marked stunting of germ-tubes of Botrytis. On the basis of previous experience with this species we can with some confidence attribute the activity to mycophenolic acid and related substances.

$P$. tardum $(2 ; 1)$. Both strains were generally antibacterial in the streak test. One was tested in liquid media, and produced slightly antibacterial culture filtrates.

$\boldsymbol{P}$. terlikowskii $(21 ; 4)$. Most of these strains agreed perfectly with the description of the species given by Raper \& Thom (1949), but six produced abundant small sclerotia, being otherwise similar. In correspondence, Dr K. B. Raper has agreed that these are the same species and that the description of the species should be expanded to cover occasional production of sclerotia. Of the twenty-one isolates tested on agar, ten were completely inactive, three inhibited all the test organisms, and the remainder inhibited Candida alone or Candida and Staph. aureus. Four were selected for test in liquid media, including ones active and inactive on agar, and sclerotial and non-sclerotial strains. All produced culture filtrates highly inhibitory to 


\section{Antibiotic production by the microfungi of acid heath soils 333}

Botrytis, B. subtilis and Bact. coli. This has been shown to be due to production of gliotoxin by both non-sclerotial (Brian, 1946) and sclerotial strains (Curtis, unpublished results).

$P$. urticae $(5 ; 1)$. One strain was inactive in the agar streak test, one inhibited all test organisms and the remainder inhibited at least two of the test organisms. One isolate was grown in liquid media and the bioassay results indicated the production of griseofulvin and some other antibiotic toxic to both fungi and bacteria; the latter is probably patulin which was obtained from this species (under the name $P$. patulum) by Anslow, Raistrick $\&$ Smith (1943).

Penicillium sp. 1006 (raistrickii series) $(1 ; 1)$. Though inactive in the streak test, in liquid media this fungus produced culture filtrates which caused a marked stunting of Botrytis germ-tubes. This organism differs from $\boldsymbol{P}$. raistrickii Smith in having smooth conidiophores and tangled conidial chains; otherwise it is very similar.

Pullularia pullulans $(3 ; 1)$. All isolates were generally antibacterial in the streak test. The one strain grown in liquid culture media produced culture filtrates inhibitory to $\boldsymbol{B}$. subtilis and slightly inhibitory to Botrytis.

Scopulariopsis sp. $809(1 ; 1)$ showed marked inhibition of Staph. aureus in the streak test but in liquid media only slight activity against $B$. subtilis was recorded.

Trichoderma viride $(140 ; 15)$. This species was isolated very frequently. There was considerable variation in colonial characters and all intermediates between 'pustulate' and 'floccose' types were found, but colonial appearance and antibiotic production were not correlated. Of the 140 isolates tested on agar, forty-five were inactive, thirty-nine inhibited all test organisms, thirty inhibited all test bacteria, fourteen inhibited Candida only and the remaining twelve inhibited one or more of the bacteria. Fifteen strains, representing all types of activity in the streak test, were grown in liquid media; four were inactive, two inhibited $B$. subtilis only and nine inhibited both Botrytis and $B$. subtilis. The impression gained from bioassay, based on previous experience with this species, was that gliotoxin and viridin probably accounted for the activity. None produced culture filtrates as potent as those from strains from which we have previously isolated viridin (Brian, Curtis, Hemming \& McGowan, 1946) and gliotoxin (Brian \& Hemming, 1945).

Verticillium sp. $1027(5 ; 3)$. All strains were inactive on agar media but in liquid media two produced appreciable antifungal and antibacterial activity.

Mycelia sterilia. Sclerotium sp. $1077(2 ; 2)$, 'fungus A' $(29 ; 1)$ and 'fungus B' $(11 ; 1)$ were inactive in both types of test.

\section{Tolerance of antibiotics by soil fungi}

The effect on germination of spores of some of the more common fungi from these soils to antibiotics produced by fungi also isolated from these soils, is shown in Table 11. The antibiotics (aurantio-gliocladin, albidin, citrinin, frequentin, griseofulvin, gliotoxin, patulin, and viridin) were made up at $50 \mu \mathrm{g} . / \mathrm{ml}$. in a germination medium (Brian \& Hemming, 1945) of $\mathrm{pH} 4.0$ and 


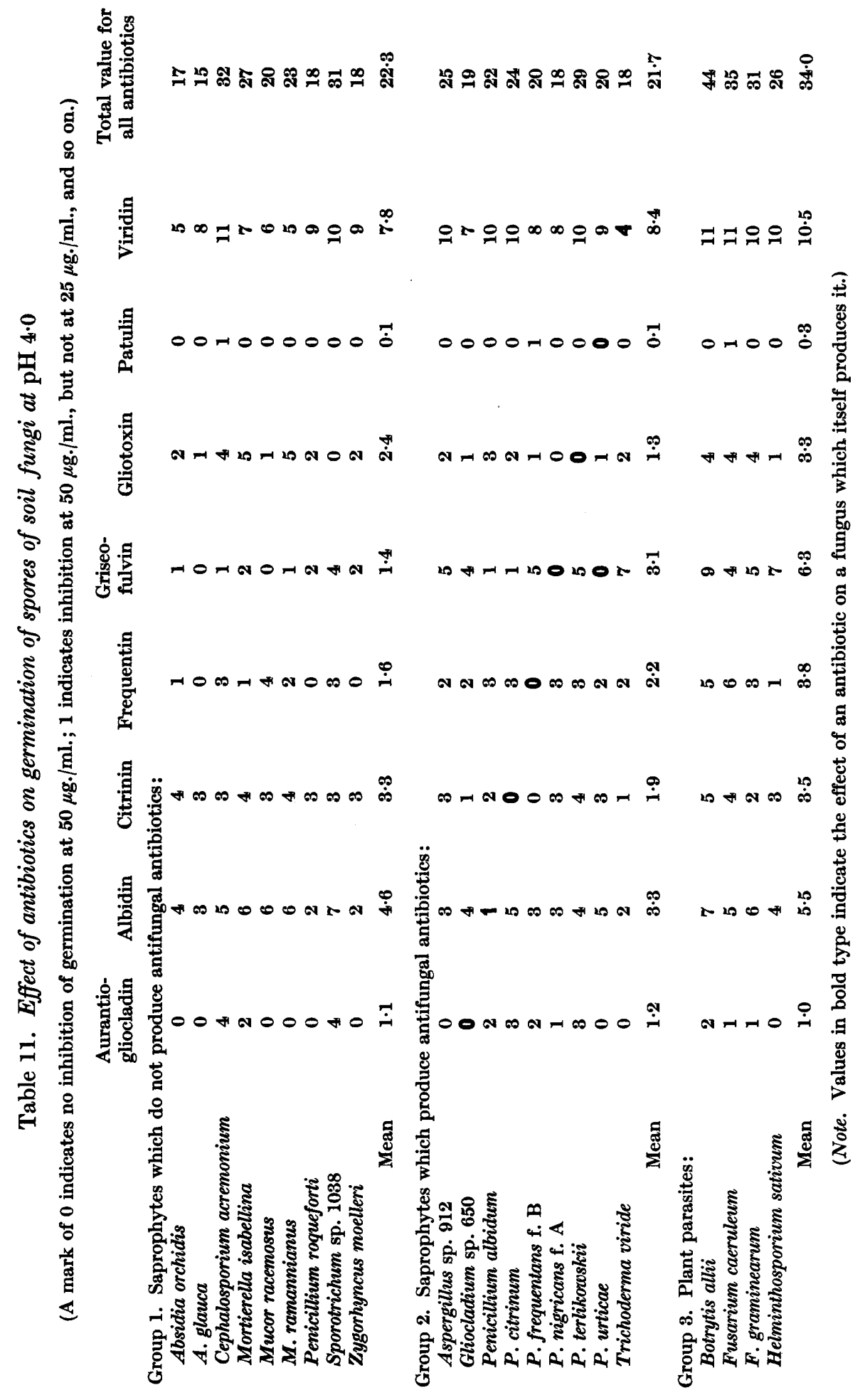




\section{Antibiotic production by the microfungi of acid heath soils 335}

spore germination tests were carried out in this medium and in a series of 1/2 dilutions. In Table 11, a value of 0 indicates less than $95 \%$ inhibition of spore germination at $50 \mu \mathrm{g} . / \mathrm{ml} ., 1$ indicates more than $95 \%$ inhibition at $50 \mu \mathrm{g} . / \mathrm{ml}$. but not at $25 \mu \mathrm{g} . / \mathrm{ml}$. and so on. In the case of griseofulvin the criterion used was not inhibition of germination, but production of a recognizable morphogenetic response in the germ-tube. A number of plantparasitic fungi, for the most part usually soil-borne, were included for purposes of comparison.

It will be seen first that the plant parasites (group 3) were on the whole the most susceptible, as has already been noted by Garrett (1950). In this group Helminthosporium sativum was anomalous in being distinctly resistant; it is perhaps significant that this species itself produces an antifungal antibiotic whereas the other species in the group do not (Brian \& Hemming, unpublished results). Secondly, a fungus which itself produces an antifungal antibiotic is in all cases markedly resistant to that antibiotic, though not necessarily to others. Thirdly, those fungi which, though of common occurrence, do not produce antifungal antibiotics (group 1), are not in general more susceptible than the antibiotic producers (group 2). Indeed, the two most generally resistant fungi, Absidia orchidis and $\boldsymbol{A}$. glauca, do not produce antifungal antibiotics.

\section{Utilization of carboxymethylcellulose}

Representative cultures of all species isolated were tested for their capacity to break down sodium carboxymethylcellulose (CMC). They were grouped as follows: (a) those unable to attack CMC (CMC - ); (b) those able to attack CMC slowly, appreciable quantities being unchanged in 14 days $(\mathrm{CMC}+)$; (c) those attacking CMC vigorously, little if any being left after 14 days' growth of the fungus $(\mathrm{CMC}++)$. Of these, category $(b)$ is probably the least reliable. The results are embodied in Table 1.

In most cases all cultures of any one species behaved similarly. Some exceptions are worthy of note. Of the seven cultures of Trichoderma viride tested, one was completely unable to utilize CMC. Of the six cultures of Cladosporium herbarum, one was completely unable to utilize CMC. Of the four cultures of Gliocladium sp. 650 tested, one attacked CMC vigorously, two attacked it slowly and one was completely unable to utilize CMC. Similar variation from vigorous attack to complete inability to attack was also seen with Penicillium spinulosum and Verticillium sp. 1027.

\section{DISCUSSION}

\section{Distribution of species}

The most widespread species, found in at least four of the nine profiles, were: Absidia orchidis, Cladosporium herbarum, Mortierella alpina, M. isabellina, Mucor ramannianus, Penicillium albidum, $P$. frequentans f. B, $P$. roqueforti, $\boldsymbol{P}$. spinulosum, $\boldsymbol{P}$. stoloniferum, $\boldsymbol{P}$. terlikowskii, $\boldsymbol{P}$. thomii, Penicillium $\mathrm{sp} .895$, Sporotrichum sp. 1038, Trichoderma viride, 'fungus A' and 'fungus B'. Of these, $T$. viride was the most commonly found. Nearly all these widely distributed species were found abundantly in at least one soil sample. 


\section{E. G. Jefferys, P. W. Brian, H. G. Hemming and D. Lowe}

The following additional species were also found abundantly in at least one soil sample but were found in less than four profiles, i.e. were locally abundant: Absidia glauca, Aspergillus sp. 912, Cephalosporium acremonium, Coniothyrium sp. 977, Gliocladium sp. 650, Penicillium adametzi, P. citrinum, Pullularia pullulans, Sclerotium sp. 1077, Scopulariopsis sp. 1005 and Zygorhyncus moelleri.

Of the widespread species, nearly all were more abundant in surface layers. Some, such as Absidia orchidis and Penicillium terlikowskii, were typically found in the $\mathbf{A}_{0}$ and $\mathbf{A}_{1}$ horizons, occurring only sporadically at lower levels. Others, such as Cladosporium herbarum, Mortierella alpina, Penicillium nigricans, $P$. roqueforti, Penicillium sp. 895 and Trichoderma viride, though usually found in surface layers, were also not infrequently found in $\mathbf{A}_{2}, \mathbf{B}$ and $\mathrm{C}$ horizons. Mucor remannianus, on the other hand, was most commonly found in the lower levels of the A horizon and in the B horizon, even occurring abundantly in the $\mathrm{C}$ horizon in some profiles. It appears to be better adapted for existence at these lower levels, and, in fact, becomes the dominant fungus in such situations. In some samples (samples 5 and 6 of profile I, samples 5, 6 and 7 of profile IV and sample 7 of profile VII) it was present in almost pure culture. Another fungus which seems to show a similar adaptation for life in lower levels of soil is Sporotrichum sp. 1038. It was present in pure culture in lower levels of the waterlogged profile IX.

The distribution of Mucor ramannianus among the various profiles is interesting. It was found as an abundant and characteristic feature in six of the nine profiles. In three profiles it was completely absent. This may be related to the occurrence of a well-marked iron pan in the B horizon, for in all such profiles $\boldsymbol{M}$. ramannianus was present and usually particularly abundant in the pan layer; in those with an ill-defined $\mathbf{B}$ horizon it was absent. This may have been purely fortuitous but is worthy of record.

There is an obvious likeness in the mould flora of the nine profiles studied and such species as Absidia orchidis, Mortierella alpina, Mucor ramannianus, Penicillium nigricans, $\boldsymbol{P}$. terlikoreskii and Trichoderma viride appear to be characteristic of these acid sandy soils. This is very similar to the mould flora found by Warcup (1951) in an acid sandy podsol (grassland E) on Lakenheath Warren, Suffolk, with two exceptions worthy of note. He found Zygorhyncus vuilleminii to be of regular occurrence. We have not found this species, though in one profile (III) we recorded what we regard as Z. moelleri, on the basis of comparison with authentic cultures from the Centraalbureau voor Schimmelcultures, Baarn, Holland. The fungus was abundant in the A horizon but absent from lower layers. This distribution is similar to that of $Z$. vuilleminii described by Warcup, in distinction from that described by Waksman (1917), who found it characteristically in the subsoil. Secondly, though Warcup found Mortierella alpina in neutral and alkaline soils, he did not find it in acid soils. He suggested, and quoted supporting data from

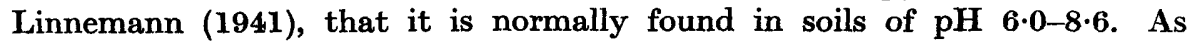

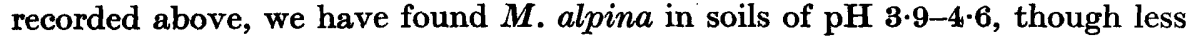
abundantly than in certain alkaline cave soils not dealt with here. Linnemann 
(1941) mentions finding it once in an acid forest soil of pH 3.7. It is remarkable that this species was found in all the Wareham profiles but in none of those from Bagshot Heath. M. isabellina also was not found in the Bagshot Heath soils though found in four of the five profiles from Wareham. It may be that the time of sampling (January for Wareham, October for Bagshot) was the decisive factor. Warcup (1951) has recorded a species of Pythium which could be isolated readily in the winter months but not at other times of the year.

\section{Antibiotic production in relation to distribution of soil fungi}

The results of experiments in liquid media probably afford a better criterion than agar streak tests of the capacity of a fungus to produce antibiotics. That criterion is therefore used exclusively in the following discussion. Of the sixty-five species isolated in this investigation, about half produce antibiotics (Table 12). Most frequently, culture filtrates (and the pure antibiotics, where

Table 12. Analysis of numbers of species of fungi from acid sandy soils producing culture filtrates on liquid media inhibitory to (a) fungi alone; (b) bacteria alone; (c) fungi and bacteria

\begin{tabular}{lccccr}
\multicolumn{1}{c}{ Group } & $\begin{array}{c}\text { No. of } \\
\text { species } \\
\text { tested }\end{array}$ & Inactive & $\overbrace{(a)}$ & $(b)$ & $(c)$ \\
Phycomycetes & 10 & 5 & 0 & 5 & 0 \\
Ascomycetes & 1 & 1 & 0 & 0 & 0 \\
Penicillia & 28 & 7 & 4 & 1 & 16 \\
Other Fungi Imperfecti & 26 & 18 & 0 & 2 & 6 \\
Total & 65 & 31 & 4 & 8 & 22
\end{tabular}

isolated) are inhibitory to both bacteria and fungi. Selective inhibition of one or the other is much less common. This preponderance of general toxicity is characteristic of the fungal antibiotics.

There is some evidence of a correlation between the capacity to produce antibiotics, especially antibiotics with antifungal properties, and the frequency of occurrence of species. This can be seen by comparing those species which we have described above as widespread species (excluding Cladosporium herbarum and Penicillium stoloniferum because of their doubtful status as soil inhabitants), those species which we have described as locally abundant species, and a group of rare species (Aspergillus ruber, Gliomastix convoluta, Mortierella vinacea, Mucor racemosus, $\boldsymbol{M}$. varians, Penicillium charlesii, $\boldsymbol{P}$. chrysogenum, $\boldsymbol{P}$. fellutanum, $\boldsymbol{P}$. lanosum, $\boldsymbol{P}$. palitans, $\boldsymbol{P}$. paxilli, $\boldsymbol{P}$. rubrum, P. tardum, Pestalotia sp. 799, Phoma spp. 802 and 1015, Pilaira anomala, Scopulariopsis spp. 809 and 1068, Torula sp. 781 and Trichocladium asperum). These rare species are all those found in not more than two samples and graded as rare in those. The percentage of species, in each of these groups, producing antifungal antibiotics are:

Widespread fungi (18 spp., 86 cultures tested)

$45 \%$

Locally abundant fungi (11 spp., 25 cultures tested)

$\mathbf{4 5} \%$

Rare fungi (21 spp., 24 cultures tested)

$15 \%$ 


\section{E. G. Jefferys, P. W. Brian, H. G. Hemming and D. Lowe}

Thus there appears to be a distinct tendency for abundance to be associated with the capacity to produce antifungal substances. It could be argued that in arriving at these figures a bias was introduced in favour of the more common species, since a species has been considered to be active even if some strains were inactive and since in general more cultures of the commoner species were examined. If a correction is made for this bias by proportionately reducing the marking for any species where some cultures were active but others inactive, the percentage of species producing antifungal substances only changes slightly, becoming 35,45 and $15 \%$ respectively.

If the capacity to produce all antibiotics is considered, i.e. including also those specifically antibacterial, the contrast between these groups is somewhat less marked, becoming (for corrected values) 49, 64 and $30 \%$ respectively.

It might be considered that this apparent tendency for antibiotic-producing fungi to be more abundant is really a reflexion of antagonism in the isolation plates, those producing antifungal antibiotics tending to inhibit the development of others. Care was taken to avoid overcrowding on the isolation plates and such an explanation seems unlikely.

At the same time it should be noted that quite a number of widespread fungi do not produce antifungal antibiotics, viz. Absidia orchidis, Mortierella alpina, M. isabellina, Mucor ramannianus, Penicillium roqueforti, $\boldsymbol{P}$. thomii, Penicillium sp. 895, Sporotrichum sp. 1038, and 'fungi A and B'. Among the locally abundant fungi, the following species do not produce antifungal antibiotics: Absidia glauca, Cephalosporium acremonium, Pullularia pullulans, Sclerotium sp. 1077, Scopulariopsis sp. 1005 and Zygorhyncus moelleri. As we have seen (Table 11), such of these species as have been examined are, as a class, resistant to the antibiotics produced by other fungi isolated from these soils, more so, for example, than a group of plant-parasitic fungi. Of course, this resistance could also be taken to explain their vigorous growth on isolation plates in the presence of antibiotic-producing fungi, but, as explained above, this interpretation is not considered adequate.

\section{Sugar fungi and humus fungi}

Burges (1939) has distinguished two ecological groups among the saprophytic soil fungi. Some can develop the necessary enzyme systems to degrade and utilize such relatively resistant plant materials as cellulose and other cell-wall constituents; they can consequently become primary invaders of such dead plant materials in the soil. Others cannot degrade such material and need much simpler carbon compounds, such as sugars, for growth; these are consequently to a great extent dependent on the activities of the former group and are only secondarily invaders of dead plant material. Burges calls these two groups humus-fungi and sugar-fungi respectively.

Using carboxymethylcellulose (CMC) as a convenient model substrate, similar to cellulose in its resistance to fungal attack (Siu, 1951), we roughly divide our species into sugar-fungi and humus-fungi. The capacity to attack CMC in vitro does not necessarily indicate a capacity to attack resistant plant residues in the soil; indeed Siu (1951) has recorded some cases of fungi 
capable of attacking cellulose or CMC in vitro which apparently cannot or do not attack cellulose in the soil. There is likely to be some correlation, nevertheless, between in vitro activity and activity in soil. Furthermore, those fungi which cannot attack CMC in vitro almost certainly will not be able to attack cellulose or other cell-wall materials in the soil and so can fairly be considered to be sugar-fungi in the sense used by Burges.

The proportions of sugar-fungi, determined in this way, in various categories of the fungi isolated are given in Table 13. These data serve to confirm the validity and importance of Burges' ecological grouping.

Table 13. Proportion (\%) of sugar-fungi (as determined by failure to degrade carboxymethylcellulose) in various categories of fungi isolated from acid sandy podsols

All fungi
Phycomycetes
Widespread fungi
Locally abundant fungi
Rare fungi
All antibiotic-producers
Antifungal antibiotic-producers
Inactive species

$\begin{array}{cc}\text { All species } & \begin{array}{c}\text { Phycomycetes } \\ \text { excluded }\end{array} \\ \mathbf{2 6} & 20 \\ \mathbf{7 0} & - \\ 17 & 0 \\ 54 & 45 \\ 33 & 35 \\ 34 & 18 \\ 17 & 17 \\ 27 & 24\end{array}$

The most striking feature of these results is that whereas only $26 \%$ of all fungi isolated can be characterized as sugar-fungi, no less than $70 \%$ of the Phycomycetes are sugar-fungi. This characteristic of the Phycomycetes is also to be seen in the data compiled by Siu (1951).

Equally striking is the very low proportion of sugar-fungi in the widespread species listed in the earlier section; apart from the Phycomycetes which fall in this category, none of the widespread fungi are sugar-fungi. It thus appears that the capacity to degrade resistant plant-materials is closely correlated with wide distribution, though certain Phycomycetes (e.g. Absidia orchidis, Mortierella alpina, M. isabellina) achieve wide distribution without that capacity.

A third noteworthy feature is that rather fewer of the fungi which produce antibiotics toxic to other fungi are sugar-fungi. This is not the case with antibiotically inactive fungi, nor with all antibiotic-producers considered together. This is largely due to a bias introduced by the Phycomycetes, which as a group combine inactivity in CMC-degradation with inability to produce antibiotics toxic to other fungi. If the Phycomycetes are ignored, there is little difference in the proportion of sugar-fungi in the various categories based on antibiotic production.

\section{CONCLUSION}

The results of this survey support the thesis that antibiotic production by soil fungi is of ecological significance. But this support is not unequivocal and is in any case indirect and circumstantial. More direct evidence is required. Organisms from this type of soil which would probably repay 


\section{E. G. Jefferys, P. W. Brian, H. G. Hemming and D. Lowe}

further investigation include the following species: Penicillium albidum, $\boldsymbol{P}$. nigricans f. A, P. terlikoroskii, P. frequentans f. B, P. citrinum, Trichoderma viride and Mucor ramannianus. A good deal is known of the antibiotics produced by some of these species, and the following are of greatest potential importance in this type of soil: albidin, griseofulvin, dechlorogriseofulvin, gliotoxin, viridin, frequentin and citrinin. We have not yet isolated an antibiotic from Mucor ramannianus; this is a matter of some interest, since no one has as yet recorded the isolation of an antibiotic from a phycomycete.

We are indebted to Mr E. W. Mason, Dr K. B. Raper and Mrs Myfanwy Turner for help in the identification of some cultures; to $\mathrm{Dr} \mathrm{J}$. H. Warcup for giving us cultures of fungi isolated from Breckland soils; to Mr P. J. Curtis for allowing us to quote some unpublished results on antibiotics produced by these fungi; to Miss Gwenda Batt, Miss Olive McMinn and Mr Ronald Weaver for technical assistance.

\section{REFERENCES}

Anslow, W. K., Raystrick, H. \& Smith, G. (1943). Antifungal substances from moulds. Part I. Patulin, a metabolic product of Penicillium patulum Bainier and P. expansum (Link) Thom. Chem. Ind., Lond. p. 236.

Birkinshaw, J. H. (1952). Studies in the biochemistry of micro-organisms. Palitantin. Part 2. Further derivatives and degradation products. Biochem. J. 51 (2), 271-5.

Brian, P. W. (1946). Production of gliotoxin by Penicillium terlikorwskii Zal. Trans. Brit. mycol. Soc. 29, 211.

Brian, P. W. (1949a). The production of antibiotics by soil micro-organisms. Chem. Ind., Lond. p. 391.

Brian, P. W. (1949b). The production of antibiotics by micro-organisms in relation to biological equilibria in soil. Symp. Soc. exp. Biol. 3, 357.

Brian, P. W. (1949c). Studies on the biological activity of griseofulvin. Ann. Bot. (N.S.), 13, 59.

Brian, P. W. (1951). Antibiotics produced by fungi. Bot. Rev. 17, 357.

Brian, P. W., Curtis, P. J. \& Hemming, H. G. (1946). A substance causing abnormal development of fungal hyphae produced by Penicillium janczeroskii Zal. I. Biological assay, production and isolation of 'curling factor'. Trans. Brit. mycol. Soc. 29, 173.

Brian, P. W., Curtis, P. J. \& Hemming, H. G. (1947). Glutinosin: a fungistatic metabolic product of the mould Metarrhizium glutinosum S. Pope. Proc. Roy. Soc. (B), 135, 106.

Brian, P. W., Curtis, P. J. \& Hemming, H. G. (1949). A substance causing abnormal development of fungal hyphae produced by Penicillium janczereskii Zal. III. Identity of 'curling-factor' with griseofulvin. Trans. Brit. mycol. Soc. 32, 30.

Brian, P. W., Curtis, P. J., Hemming, H. G., Jefferys, E. G., Unwin, C. H. \& Wright, J. M. (1951). Alternaric acid; a biologically active metabolic product of Alternaria solani (Ell. \& Mart.) Jones \& Grout; its production, isolation and antifungal properties. J. gen. Microbiol. 5, 619.

Brian, P. W., Curtis, P. J., Hemming, H. G. \& MeGowan, J. C. (1946). The production of viridin by pigment-forming strains of Trichoderma viride. Ann. appl. Biol. 33, 190.

Brian, P. W., Curtis, P. J., Howland, S. R., Jefferys, E. G. \& Raudnitz, H. (1951). Three new antibiotics from a species of Gliocladium. Experientia, 7, 266. 


\section{Antibiotic production by the microfungi of acid heath soils 341}

Brian, P. W. \& Hemming, H. G. (1945). Gliotoxin, a fungistatic metabolic product of Trichoderma viride. Ann. appl. Biol. 32, 214.

Brian, P. W., Hemming, H. G. \& McGowan, J. C. (1945). Origin of a toxicity to mycorrhiza in Wareham Heath soil. Nature, Lond. 155, 637.

Burges, A. (1939). Soil fungi and root infection. Broteria, 8, 64.

Curtis, P. J. \& Duncanson, L. A. (1952). A structural relationship between frequentin and palitantin. Biochem. J. 51, 276.

Curtis, P. J., Hemming, H. G. \& Smith, W. K. (1951). Frequentin: an antibiotic produced by some strains of Penicillium frequentans Westling. Nature, Lond. $167,557$.

Curtis, P. J., Hemming, H. G. \& Unwin, C. H. (1951). Albidin, an antibiotic red pigment from Penicillium albidum. Trans. Brit. mycol. Soc. 34, 332.

CurTis, P. J. \& Grove, J. F. (1947). A fungistatic and bacteriostatic red pigment produced by a strain of the Penicillium nigricans-janczewskii series. Nature, Lond. 160, 574.

GarretT, S. D. (1950). Ecology of the root inhabiting fungi. Biol. Rev. 25, 220.

GARRETT, S. D. (1951). Ecological groups of soil fungi: a survey of substrate relationships. New Phytol. 50, 149.

Gatenby, J. B. \& Beams, H. W. (1950). The Microtomist's Vade-mecum. 11th ed. London: J. and A. Churchill Ltd.

Grove, J. F. \& Brian, P. W. (1951). Identity of frequentic acid and citromycetin. Nature, Lond. 167, 995.

Grove, J. F. \& McGowaN, J. C. (1947). Identity of griseofulvin and 'curling factor'. Nature, Lond. 160, 574.

Grove, J. F., MacMrllan, J., Mulholland, T. P. C. \& Rogers, M. A. T. (1952). Griseofulvin. Part IV. Structure. J. chem. Soc. p. 3977.

Jefrerys, E. G. (1952). The stability of antibiotics in soils. J. gen. Microbiol. 7, 295.

Linnemann, G. (1941). Die Mucorineen-Gattung Mortierella Coemans. Jena: Gustav Fischer.

MacMintan, J. (1951). Dechlorogriseofulvin-a metabolic product of Penicillium griseofulvum Dierckx and Penicillium janczereskii Zal. Chem. Ind., Lond. p. 719.

Naumov, N. A. (1939). Clés des Mucorinées. Paris: Paul Lechevalier.

NerLson-Jones, W. (1941). Biological aspects of soil fertility. J. agric. Sci. 31, 379.

RAper, K. B. \& Thom, C. (1949). A Manual of the Penicillia. London: Baillière, Tindall and Cox.

RAYNER, M. C. (1945). Origin of a toxicity to fungi in Wareham Heath soil. Nature, Lond. 156, 174.

Siv, R. G. H. (1951). Microbial Decomposition of Cellulose. New York: Reinhold Publishing Corporation.

Thом, C. \& RAPER, K. B. (1945). A Manual of the Aspergilli. London: Baillière, Tindall and Cox.

Vischer, E. B. (1953). The structures of aurantio- and rubro-gliocladin and gliorosein. J. chem. Soc. p. 815.

Waksman, S. A. (1917). Is there any fungus flora of the soil? Soil Sci. 3, 565 .

WARCUP, J. H. (1951). The ecology of soil fungi. Trans. Brit. mycol. Soc. 34, 376.

Wright, J. M. (1952). Production of gliotoxin in unsterilized soil. Nature, Lond. $170,678$.

ZychA, H. (1935). Mucorineae. (Bd. vI: Kryptogamenflora der Mark Brandenburg.) Leipzig: Gebrüder Borntraeger.

(Received 29 April 1953) 